\title{
Dracorhodin perchlorate induces apoptosis and G2/M cell cycle arrest in human esophageal squamous cell carcinoma through inhibition of the JAK2/STAT3 and AKT/FOXO3a pathways
}

\author{
ZHENGYANG LU ${ }^{1}$, CHENYANG LU ${ }^{2}$, CHENG LI $^{3}$, YAN JIAO ${ }^{4}$, YANQING LI ${ }^{5}$ and GUANGXIN ZHANG ${ }^{6}$ \\ ${ }^{1}$ Department of General Surgery, The Second Hospital of Jilin University, Changchun, Jilin 130041; \\ ${ }^{2}$ Department of Respiratory Medicine, Third Hospital of Xi'an, Xi'an, Shaanxi 710082; \\ ${ }^{3}$ Department of Cardiovascular Medicine, The First Hospital of Jilin University; \\ ${ }^{4}$ Department of Hepatobiliary and Pancreatic Surgery, The First Hospital of Jilin University; \\ ${ }^{5}$ Department of Pathophysiology, College of Basic Medical Sciences, Jilin University, Changchun, Jilin 130021; \\ ${ }^{6}$ Department of Thoracic Surgery, The Second Hospital of Jilin University, Changchun, Jilin 130041, P.R. China
}

Received September 7, 2018; Accepted March 15, 2019

DOI: $10.3892 / \mathrm{mmr} .2019 .10474$

\begin{abstract}
Dracorhodin perchlorate (DP), a synthetic analogue of the anthocyanin red pigment dracorhodin, has been shown to exert various pharmacological effects, including anticancer activity. However, its effects on human esophageal squamous cell carcinoma (ESCC) cells have not been previously investigated, and the molecular mechanisms underlying its anticancer activity remain unclear. In the present study, it was demonstrated that DP significantly reduced the viability of ESCC cells compared with that noted in normal human liver LO2 cells. Treatment with DP induced G2/M phase cell cycle arrest through upregulation of p21 and p27, and downregulation of cyclin B1 and Cdc2. Furthermore, DP treatment induced caspase-dependent apoptosis, which could be reversed by exposure to Z-VAD-FMK, a caspase inhibitor. Western blotting demonstrated that DP induced apoptosis through extrinsic and intrinsic pathways by upregulating death receptor 4 (DR4), DR5, cleaved caspase-3/-7/-9 and cleaved poly (ADP-ribose) polymerase (PARP), and by decreasing total PARP, total caspase-3/7, Bcl-2 and caspase-9/-10. Moreover, DP treatment decreased the phosphorylation of Janus kinase 2 (JAK2), signal transducer and activator of transcription 3 (STAT3), AKT, and forkhead box O3a (FOXO3a) in ESCC cells, indicating that the activity of the JAK2/STAT3 and AKT/FOXO3a signaling pathways was inhibited. Therefore, DP is a promising therapeutic agent for ESCC.
\end{abstract}

Correspondence to: Dr Guangxin Zhang, Department of Thoracic Surgery, The Second Hospital of Jilin University, 218 Ziqiang Street, Changchun, Jilin 130041, P.R. China

E-mail: zhangguangxin_409@163.com

Key words: dracorhodin perchlorate, cell cycle arrest, apoptosis, STAT3, AKT

\section{Introduction}

Human esophageal cancer is a commonly diagnosed disease worldwide, with an increasing incidence estimated at more than 450,000 new cases each year (1). Two important types of human esophageal cancer have been identified, including squamous cell carcinoma and adenocarcinoma, in which, esophageal squamous cell carcinoma has a higher prevalence in China (2). Several therapeutic approaches have been developed for esophageal cancer in recent decades, including endoscopic resection and surgery; however, these approaches show some efficacy only during the early stages of esophageal cancer $(3,4)$. Radiotherapy and chemotherapy are more commonly used for advanced stages, but their efficacy remains unsatisfactory due to the development of therapeutic resistance and unavoidable side effects $(4,5)$. Recently, numerous studies have demonstrated that compounds isolated from traditional Chinese medicines, such as osthole, bufadienolides, matrine, and the ajoene analogue BisPMB, exhibit anti-esophageal cancer activity through the induction of apoptosis, cell cycle arrest and endoplasmic reticulum stress (6-9). Consequently, the development of new treatment agents from traditional Chinese medicine is becoming a promising strategy for the treatment of esophageal cancer.

Dracorhodin perchlorate (DP) (Fig. 1A) is a synthetic analogue of the anthocyanin red pigment dracorhodin, which is extracted from exudates of the fruit of Daemonorops draco, also known as 'dragon's blood' in traditional Chinese medicine $(10,11)$. It has been reported to exert a variety of physiological and pharmacological effects, such as antimicrobial and antifungal activity and promotion of wound healing (11-14). Recently, there has been increasing interest in the anticancer properties of DP, which have been demonstrated in several studies undertaken on various types of malignant cells. For example, DP was reported to induce apoptosis in human gastric adenocarcinoma through inactivation of the AKT/FOXO3a and NF- $\mathrm{B}$ signaling pathways (15) and through activation of the $\mathrm{p} 38 / \mathrm{JNK}$ MAPK signaling pathways 
in human melanoma cells (16). In addition to apoptosis, DP has also been shown to induce cell cycle arrest in various types of cancer cells $(15,17)$. However, the effect of DP on ESCC remains unknown, and the molecular mechanisms underlying the anticancer properties of DP warrant further investigation.

In our previous study, DP induced intrinsic apoptosis and G1 phase arrest and upregulated p53 in human lung squamous carcinoma cells (18). In the present study, the potential antitumor effects of DP were investigated on ESCC cells, as well as the associated underlying mechanisms. The results showed that DP significantly inhibited the proliferation of ESCC cells, while exerting a low cytotoxic effect on normal human liver LO2 cells. Furthermore, DP induced apoptosis and G2 phase arrest, and inhibited the activation of the JAK2/STAT3 and AKT/FOXO3a pathways in ESCC cells.

\section{Materials and methods}

Reagents. Dracorhodin perchlorate (DP) was purchased from ShangHai YuanYe Biotechnology Co., Ltd. (Shanghai, China) and dissolved in dimethyl sulfoxide (DMSO). Fetal bovine serum (FBS) and the enhanced chemiluminescence (ECL) kit were purchased from Thermo Fisher Scientific, Inc. (Waltham, MA, USA). Phosphate-buffered saline (PBS), RPMI-1640, and penicillin-streptomycin were purchased from HyClone/GE Healthcare Life Sciences (Victoria, Australia). The Giemsa stain kit was purchased from Beijing Solarbio Science \& Technology (Beijing, China). Cell Counting Kit-8 (CCK-8) was purchased from Dojindo Labortories (Kumamoto, Japan). Hoechst 33342 and the Cell Cycle Analysis kit were purchased from Beyotime Institute of Biotechnology (Shanghai, China). The FITC/Annexin V Apoptosis Detection kit was purchased from BD Biosciences (Franklin Lakes, NJ, USA). The broad-spectrum caspase inhibitor (Z-VAD-FMK) was purchased from Sigma-Aldrich (Merck KGaA, Darmstadt, Germany). Primary antibodies against $\beta$-actin (1:2,000; cat. no. 4970T), Bcl-2 (1:1,000; cat. no. 4223T), caspase-9 (1:500; cat. no. 9508S.), cleaved caspase-3 (1:500; cat. no. 9661T), cleaved caspase-7 (1:500; cat. no. 8438T), total caspase-3 (1:1,000; cat. no. 9662S), total caspase-7 (1:1,000; cat. no. 12827T), DR4 (1:1,000; cat. no. 42533S), DR5 (1:1,000; cat. no. 8074T), cyclin B1 $(1: 1,000$; cat. no. 12231T), Cdc2 (1:1,000; cat. no. 9116T), AKT (1:1,000; cat. no. 4691T), and p-AKT (Ser473; (1:500; cat. no. 4060T) were purchased from Cell Signaling Technology (Danvers, MA, USA). Primary antibodies against PARP (1:1,000; cat. no. ab32138), caspase-10 (1:1,000; cat. no. ab32155), p21 (1:1,000; cat. no. ab188224), p27 (1:1,000; cat. no. ab92741), JAK2 (1:1,000; cat. no. ab108596), p-JAK2 (Tyr1007/1008; 1:500; cat. no. ab32101), STAT3 (1:1,000; cat. no. ab68153), p-STAT3 (Tyr705; 1:500; cat. no. ab76315), FOXO3a (1:1,000; cat. no. ab109629), and p-FOXO3a (Ser253; (1:500; cat. no. ab154786) were purchased from Abcam (Cambridge, MA, USA). Goat Anti-rabbit (1:5,000; cat. no. sc-2004) and goat anti-mouse (1:5,000; cat. no. sc-2005) secondary antibodies were purchased from Santa Cruz Biotechnology (Santa Cruz, CA, USA).

Cells and cell culture. Human ESCC cell lines (ECA109, EC9706 and KYSE410) were purchased from Shanghai GeneChem Co., Ltd. (Shanghai, China). Normal human liver LO2 cells were a kind gift from Dr Yan Jiao from Jilin University (Jilin, China). All the cells were maintained in a humidified atmosphere with $5 \% \mathrm{CO}_{2}$. Cells were cultured in RPMI-1640 medium supplemented with $10 \%$ FBS.

Cell viability assay. Cell viability was evaluated using a CCK- 8 assay. Briefly, $5 \times 10^{3}$ cells were plated in a 96 -well plate and cultured for 1 day for cell attachment. Next, the cells were treated with various concentrations of DP $(10-100 \mu \mathrm{M})$ for $24 \mathrm{~h}$, and then $10 \mu \mathrm{l} \mathrm{CCK}-8$ was added to the cells, followed by a 2 -h incubation at $37^{\circ} \mathrm{C}$. Finally, the absorbance was detected at $450 \mathrm{~nm}$ using a microplate reader.

Colony formation assay. A total of $4 \times 10^{5}$ cells/well were seeded in a 6-well plate and cultured overnight. The cells were then exposed to various concentrations of DP $(0-80 \mu \mathrm{M})$ for $24 \mathrm{~h}$. Subsequently, the cells were harvested and counted, and then plated at 400 cells/well in a 6 -well plate and cultured for 2 weeks for colony formation. The cells were then washed twice with PBS, fixed with $4 \%$ paraformaldehyde for $20 \mathrm{~min}$, and stained with Giemsa stain for $30 \mathrm{~min}$ at room temperature followed by two washes with PBS. Finally, positive colonies containing more than 50 cells were counted under an optical microscope (magnification, x100).

Analysis of apoptosis by flow cytometry. The effect of DP on cell apoptosis was measured by Annexin V-FITC/propidium iodide (PI) staining. Briefly, $4 \times 10^{5}$ cells/well were seeded in a 6 -well plate. After overnight culture and attachment, the cells were treated with 0,40 and $80 \mu \mathrm{M}$ DP for $24 \mathrm{~h}$. The cells were then harvested, washed twice with PBS and resuspended in $400 \mu \mathrm{l}$ binding buffer. Next, $5 \mu \mathrm{l}$ Annexin V-FITC/PI was added to the cell suspension, and the cells were incubated in the dark at $37^{\circ} \mathrm{C}$ for $15 \mathrm{~min}$. Finally, apoptosis was measured by flow cytometry.

Morphological evaluation of apoptosis. The morphological detection of apoptosis was performed with Hoechst 33342 staining. Briefly, $4 \times 10^{5}$ cells/well were seeded in a 6 -well plate. After overnight culture and attachment, the cells were treated with 0 and $80 \mu \mathrm{M}$ DP for $24 \mathrm{~h}$. The cells were then collected in a centrifuge tube and washed twice with PBS. Subsequently, $200 \mu 1$ of Hoechst 33342 was added, followed by incubation at $37^{\circ} \mathrm{C}$ for $30 \mathrm{~min}$. Finally, the cells were mounted on a glass slide for morphological analysis of apoptosis under a fluorescence microscope.

Cell cycle analysis by flow cytometry. The effect of DP on the cell cycle was measured by flow cytometry using PI staining. Briefly, $4 \times 10^{5}$ cells/well were seeded in a 6-well plate and incubated at $37^{\circ} \mathrm{C}$ overnight for cell attachment. The cells were then treated with 0,40 and $80 \mu \mathrm{M}$ DP for a further $24 \mathrm{~h}$. The cells were subsequently harvested in a centrifuge tube and fixed with $500 \mu \mathrm{l}$ of $70 \%$ ice-cold ethanol at $4^{\circ} \mathrm{C}$ for $4 \mathrm{~h}$. The cells were washed twice with PBS and then incubated in the dark with $10 \mu \mathrm{l}$ RNase A and $25 \mu \mathrm{l}$ PI staining solution at $37^{\circ} \mathrm{C}$ for $30 \mathrm{~min}$. Finally, the cell samples were analyzed by flow cytometry.

Western blotting. Protein expression was detected by western blotting. Briefly, $1 \times 10^{6}$ cells were seeded in $60-\mathrm{mm}$ dishes 
and cultured overnight for attachment. After treatment with 0, 40, 60 and $80 \mu \mathrm{M}$ DP for $24 \mathrm{~h}$, the cells were harvested and washed twice with PBS. The cells were then suspended in protein extraction buffer containing protease inhibitors, and lysed on ice for $30 \mathrm{~min}$. The supernatant was collected after centrifugation at $13,000 \mathrm{x} \mathrm{g}$ for $10 \mathrm{~min}$, and the protein content was measured using a bicinchoninic acid protein assay kit. Equal amounts of protein lysates $(20 \mu \mathrm{g})$ were separated by electrophoresis on a $10-15 \%$ sodium dodecyl sulphate-polyacrylamide gel at $120 \mathrm{~V}$. The proteins were then transferred onto polyvinylidene difluoride membranes (EMD Millipore, Billerica, MA, USA), which were then soaked in blocking buffer (5\% skimmed milk) for $1 \mathrm{~h}$. The membranes were then incubated with the relevant primary antibodies overnight at $4^{\circ} \mathrm{C}$, followed by incubation with the appropriate horseradish peroxidase-conjugated secondary antibodies for $1 \mathrm{~h}$ at room temperature. Finally, ECL detection was performed. $\beta$-actin was used as reference protein. Grey values of the protein bands were measured by Image $\mathbf{J}$ version 1.5.1 (National Institutes of Health, Bethesda, MD, USA).

Statistical analysis. All the experiments were repeated 3 times. Data were analyzed using SPSS version 19.0 statistical software (IBM Corp., Armonk, NY, USA) and expressed as the mean \pm standard deviation. Comparisons between groups were analyzed using the unpaired Student's t-test or one-way analysis of variance (ANOVA) followed by Tukey's post hoc tests. $\mathrm{P}<0.05$ was considered statistically significant.

\section{Results}

$D P$ reduces the viability of ESCC cells. To determine the effect of DP on ESCC cells, a Cell Counting Kit-8 (CCK-8) assay was performed to evaluate the viability of three ESCC cell lines (ECA109, EC9706 and KYSE410). As shown in Fig. 1B, exposure to DP at concentrations ranging from 0 to $100 \mu \mathrm{M}$ for 24 and $48 \mathrm{~h}$ significantly decreased the viability of all three ESCC cell lines in a concentration- and time-dependent manner. Furthermore, DP cytotoxicity was compared between the ECA109 and normal human liver LO2 cell lines. As shown in Fig. 1C, after treatment for $24 \mathrm{~h}$, DP at $80 \mu \mathrm{M}$ showed reduced toxicity towards LO2 cells compared with the ECA109 cells. These results indicated that DP has increased selective cytotoxicity towards ESCC cells compared to normal human cells.

$D P$ inhibits the colony-forming ability of ESCC cells. To investigate the effect of DP on long-term proliferation of ESCC cells, a colony formation assay was performed. After treatment with DP $(0,40,60$ and $80 \mu \mathrm{M})$ for $24 \mathrm{~h}$, the treated cells were reseeded in a 6 -well plate with 400 cells/well and cultured for 14 days. As shown in Fig. 2A, the colony-forming ability of the ECA109 and EC9706 cells decreased significantly in a concentration-dependent manner compared with control group. In addition, morphological changes in ECA109 and EC9706 cells after treatment with DP (0, 40, 60 and $80 \mu \mathrm{M})$ were observed under an optical microscope. As shown in Fig. 2B, the cells became round and small, and floating cells were also observed with increasing concentrations.
DP induces G2 phase arrest in ESCC cells. Cell cycle arrest is a mechanism that potentially mediates the anticancer effect of many drugs. To determine the effect of DP on cell cycle progression, DP-treated ECA109 and EC9706 cells stained with PI were analyzed by flow cytometry. As shown in Fig. 3A and B, after treatment with DP for $24 \mathrm{~h}$, the proportion of cells in the G2/M phase significantly increased compared with the control group, accompanied by a corresponding decrease in G0/G1 and S phase populations. Furthermore, the underlying molecular mechanism was explored by detecting the expression of $\mathrm{G} 2 / \mathrm{M}$ phase-related proteins using western blotting. As shown in Fig. 3C-F, after DP treatment, p21 and p27 were upregulated and cyclin $\mathrm{B} 1$ and $\mathrm{Cdc} 2$ were downregulated in a concentration- and time-dependent manner compared with the control group in ECA109 cells. Taken together, our results showed that DP induced G2 phase arrest in ESCC cells through upregulation of p21 and p27, and downregulation of cyclin B1 and Cdc2.

DP induces caspase-dependent apoptosis in ESCC cells. Apoptosis is an important target for the cancer inhibitory effects of chemotherapeutic drugs. To determine whether apoptosis is induced by DP treatment, Annexin V-FITC/PI double staining was performed, followed by flow cytometry. As shown in Fig. 4A, DP treatment $(0,40$ and $80 \mu \mathrm{M})$ for $24 \mathrm{~h}$ significantly increased the proportion of apoptotic ECA109 and EC9706 cells. In addition, pretreatment for $1 \mathrm{~h}$ with Z-VAD-FMK, a broad-spectrum caspase inhibitor, significantly reversed apoptosis induced by DP $(80 \mu \mathrm{M})$ compared to $80 \mu \mathrm{M}$ DP treatment alone.

Apoptotic cells often exhibit typical morphological changes, characterized by chromatin condensation and DNA fragmentation. To further confirm DP-induced apoptosis, Hoechst 33342 staining assay was used to assess cell morphological changes. After $80 \mu \mathrm{M}$ DP treatment for $24 \mathrm{~h}$, chromatin condensation and DNA fragmentation were observed in ECA109 and EC9706 cells, as indicated by the arrow in Fig. 4B.

The role of DP-induced apoptosis in the anti-proliferative effect of this compound was analyzed through pretreatment of ECA109 cells with Z-VAD-FMK before co-incubation with $80 \mu \mathrm{M}$ DP for $24 \mathrm{~h}$. The results showed that Z-VAD-FMK significantly attenuated the DP-induced reduction in cell viability to $59.8 \%$ in ECA109 cells, compared with $36.2 \%$ for DP $(80 \mu \mathrm{M})$ treatment alone (Fig. 4C). These results indicate that DP induced apoptosis in a caspase-dependent manner and consequently exhibited a cytotoxic effect in ESCC cells.

DP induces apoptosis through the extrinsic and intrinsic pathways in ECA109 cells. Caspase-dependent apoptosis is characterized by the activation of a caspase cascade, in which caspase-3 and caspase-7 function as executioner caspases. When caspase- 3 and caspase- 7 are activated, the active forms cleave several cellular substrates, including PARP, the cleavage of which is also regarded as a typical molecular apoptotic marker. To study the molecular mechanisms involved in DP-induced apoptosis, the levels of total PARP, total caspase-3/7, cleaved PARP, and cleaved caspase-3/-7 were determined by western blotting. As shown in Fig. 5A and B, DP treatment for $24 \mathrm{~h}$ significantly decreased total PARP and 
A<smiles>COc1c(C)c(O)cc2[o+]c(-c3ccccc3)ccc12</smiles>

C

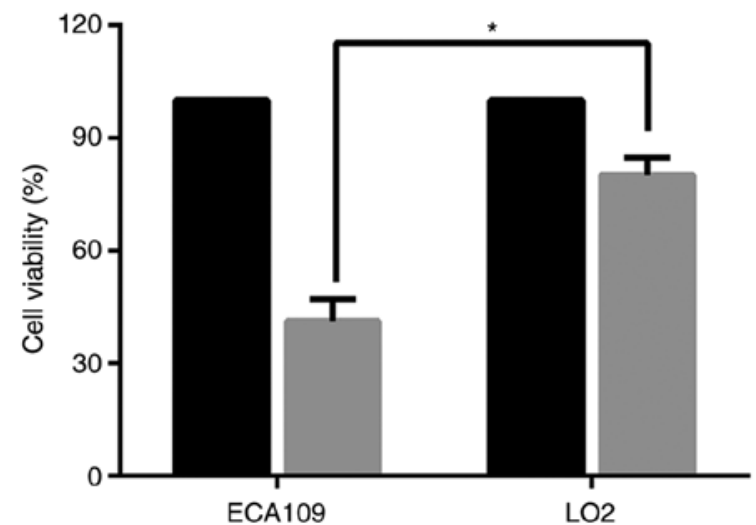

ECA109
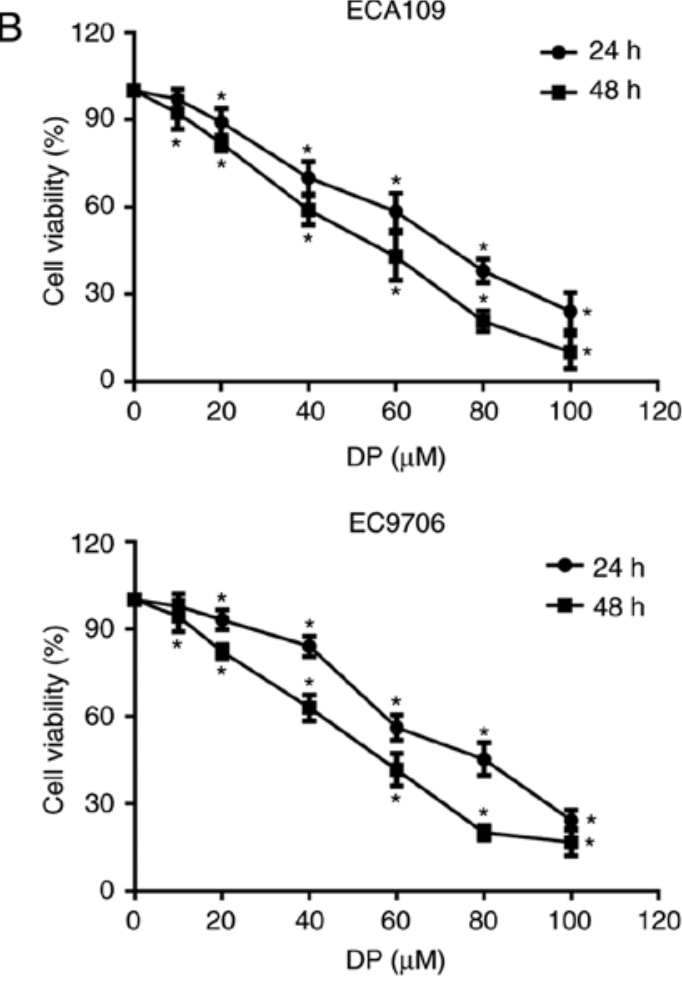

KYSE410

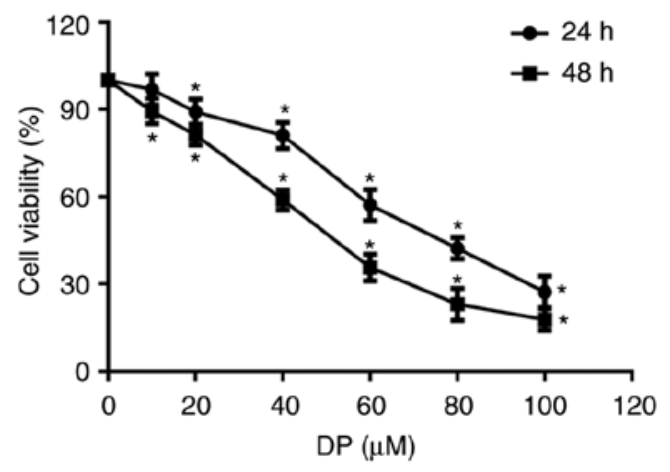

Figure 1. DP reduces the viability of ESCC cells. (A) Chemical structure of DP. (B) The effect of DP on the viability of ESCC cells (ECA109, EC9706 and KYSE410) was detected by CCK-8 assay. (C) A total of $80 \mu \mathrm{M}$ DP treatment selectively reduced cell viability of ECA109 cells, while this dose showed lower cytotoxicity in human liver normal LO2 cells. The data are expressed as the mean \pm standard deviation $(\mathrm{n}=3)$. " $\mathrm{P}<0.05$ compared with the control group. DP, dracorhodin perchlorate; ESCC, esophageal squamous cell carcinoma; CCK-8, Cell Counting Kit-8.

total caspase-3/7 expression levels and increased the expression levels of cleaved PARP and cleaved caspase-3/-7 in a concentration-dependent manner in ECA109 cells.

To further investigate which apoptotic pathway is involved in DP-induced apoptosis, the expression of several extrinsic and intrinsic apoptosis-related proteins was determined by western blotting. After treatment of ECA109 cells with increasing concentrations of DP $(0-80 \mu \mathrm{M})$ for $24 \mathrm{~h}$, extrinsic and intrinsic apoptosis were both activated, as demonstrated by the upregulation of DR4, DR5 and cleaved caspase-9, and the downregulation of caspase-9, caspase-10 and Bcl-2 (Fig. 5C and D). In addition, the levels of the Bid protein, which can transduce the extrinsic apoptotic signal to mitochondria to trigger intrinsic apoptosis when activated by cleavage, was decreased after DP treatment (Fig. 5C and D), suggesting the presence of a crosstalk between extrinsic and intrinsic apoptosis in DP-treated ECA109 cells.
DP inhibits the JAK2/STAT3 and AKT/FOXO3a signaling pathways in ECA109 ESCC cells. Research has shown that the STAT3 and AKT signaling pathways are closely associated with cell proliferation and are overactivated in a variety of cancers. Therefore, in the present study, we investigated whether these two signaling pathways were affected by DP treatment. After treatment of ECA109 cells with DP for $24 \mathrm{~h}$, western blot analysis was performed to assess the expression and phosphorylation of the related proteins. As shown in Fig. 6A, B and E, the expression of JAK2 and STAT3 was decreased slightly, while their phosphorylation and the ratio of phosphorylated protein/total protein of JAK2 and STAT3 was significantly reduced. In addition, DP treatment also decreased the phosphorylation and the ratio of phosphorylated protein/total protein of AKT and FOXO3a, but had little effect on the expression of these proteins (Fig. 6C-E). These data 
A
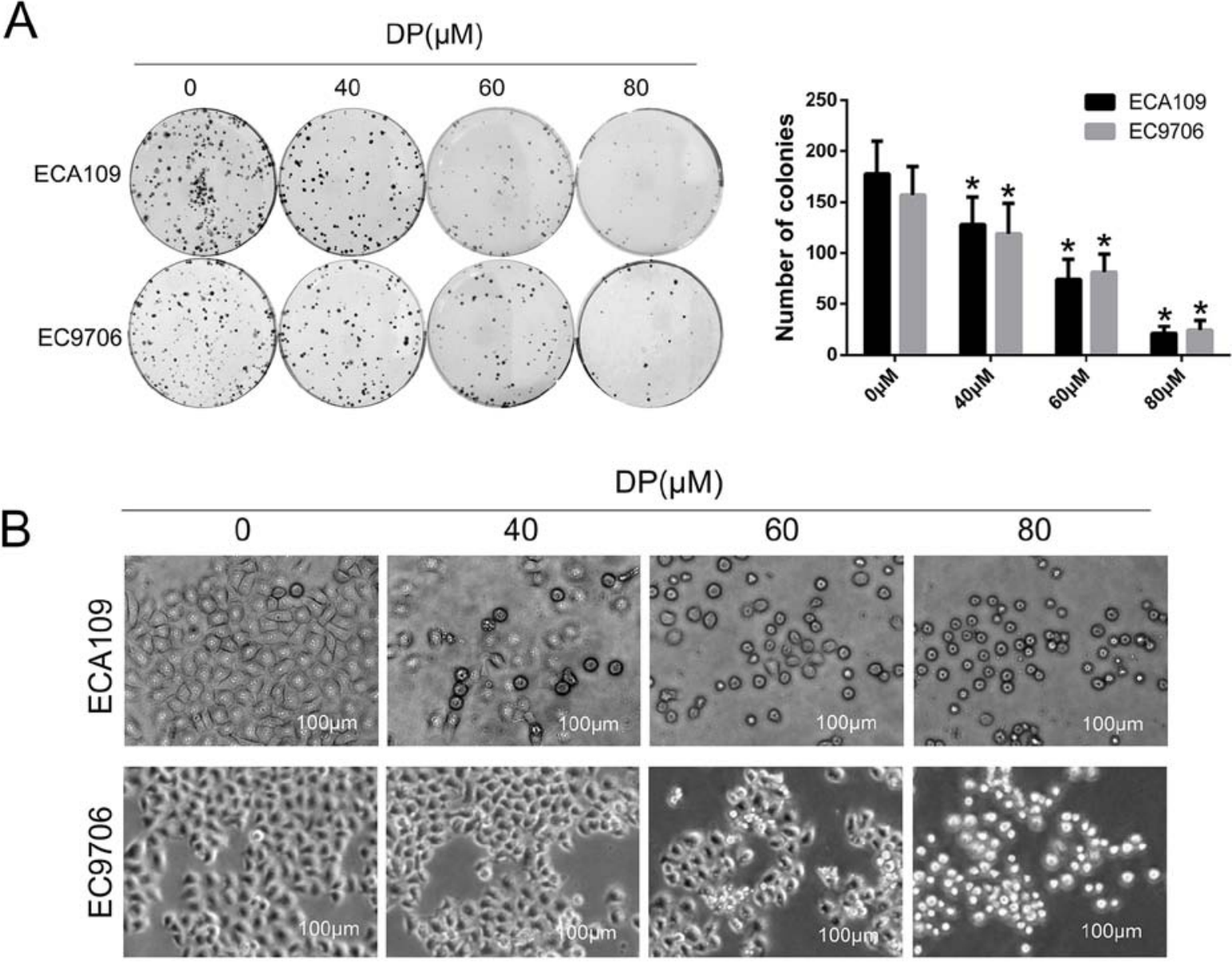

Figure 2. DP inhibits the colony formation ability of ESCC cells. (A) After treatment with DP (0, 40, 60 and $80 \mu \mathrm{M})$ for 24 h, and reseeding cells in 6-well plate with 400 cells/well following 14 days of incubation, the colony formation ability of ECA109 and EC9706 cells was significantly decreased. Both images and quantitative data are presented. (B) Round and shrunken cells were observed under ordinary optical microscopy after treatment with DP (0, 40,60 and $80 \mu \mathrm{M}$ ) for $24 \mathrm{~h}$ in ECA109 and EC9706 cells. The data are expressed as the mean \pm standard deviation ( $\mathrm{n}=3$ ). ${ }^{*} \mathrm{P}<0.05$ compared with the control group. DP, dracorhodin perchlorate; ESCC, esophageal squamous cell carcinoma.

suggest that apoptosis and cell cycle arrest induced by DP in ESCC cells were partly due to the inactivation of JAK2/STAT3 and AKT/FOXO3a.

\section{Discussion}

The development of new anticancer agents derived from traditional Chinese medicine is becoming an attractive strategy for the treatment of various types of cancer. Dracorhodin perchlorate (DP), a synthetic analogue of the anthocyanin red pigment dracorhodin isolated from exudates of the fruit of Daemonorops draco, has previously been shown to exert a robust anticancer effect in various cancer cell lines (15,17-19). However, the underlying mechanism of this effect has not been fully elucidated, and the effect of DP on esophageal squamous cell carcinoma (ESCC) cells remains unknown. In the present study, DP was observed to inhibit cell proliferation through the induction of apoptosis and $\mathrm{G} 2 / \mathrm{M}$ phase cell cycle arrest and to inhibit the activation of the JAK2/STAT3 and AKT/FOXO3a signaling pathways.

It is well known that abnormal cell cycle progression, with a consequent loss of key cell cycle checkpoints, results in over-proliferation of cancer cells (20-22). Therefore, we explored whether induction of cell cycle arrest was one of the mechanisms involved in the inhibitory effect of DP on the proliferation of ESCC cells. In the present study, it was found that DP treatment significantly induced cell cycle arrest at the $\mathrm{G} 2 / \mathrm{M}$ phase in a concentration-dependent manner. Moreover, our results also showed that DP induced G2/M phase arrest by regulating the expression of various proteins that control the transition from the $\mathrm{G} 2 / \mathrm{M}$ phase to the $\mathrm{G} 0 / \mathrm{G} 1$ phase $(23,24)$, such as by upregulating p21 and p27 and downregulating cyclin B1 and Cdc2. Previous studies have also reported that DP induced cell cycle arrest at the G0/G1 phase in human lung squamous carcinoma cells and human gastric adenocarcinoma cells $(15,18)$. Collectively, together with the results from the present study, these findings indicate that, depending on cell type, induction of cell cycle arrest at different phases is one potential anticancer mechanism of DP.

Apoptosis is the most common target in the development of new anticancer drugs $(25,26)$. There are two major apoptotic pathways, namely the extrinsic pathway mediated by DRs, and the intrinsic pathway regulated by the Bcl-2 family (27). The caspase cascade is important for the initiation and execution of apoptosis, where caspase-10 and -8 initiate extrinsic apoptosis, caspase- 9 initiates intrinsic apoptosis, and caspase-3 and -7 are the executioner caspases (28). In the present study, both extrinsic and intrinsic apoptosis were induced by DP treatment 
A

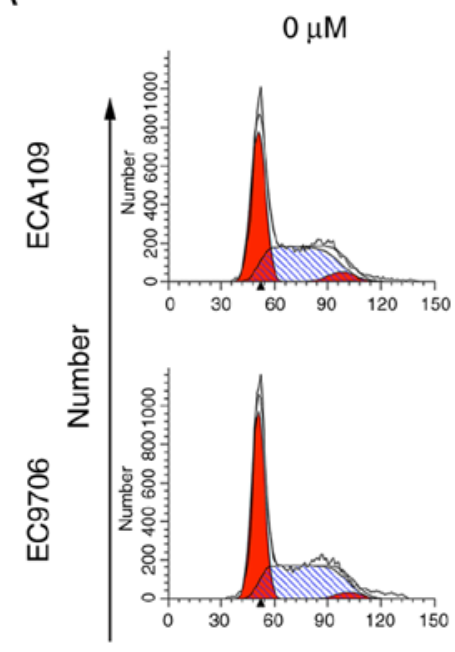

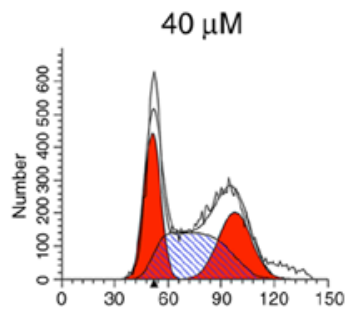
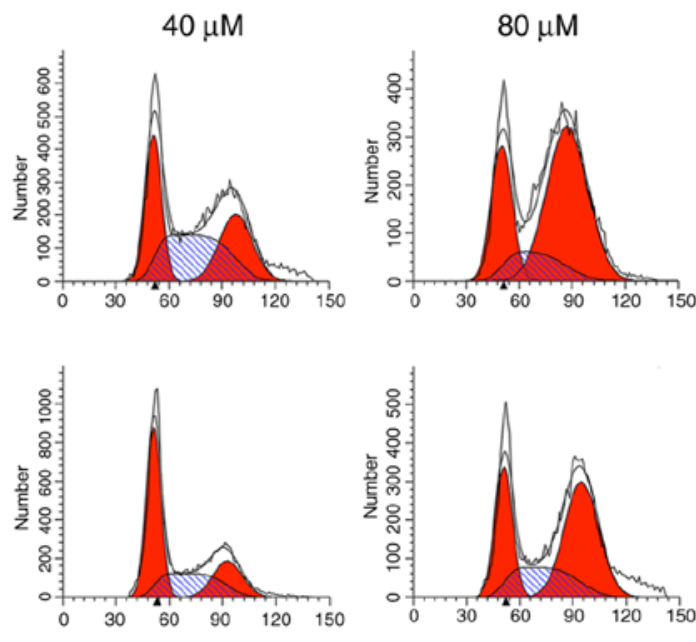

Channels (FL2-A)

C DP $(\mu \mathrm{M})$

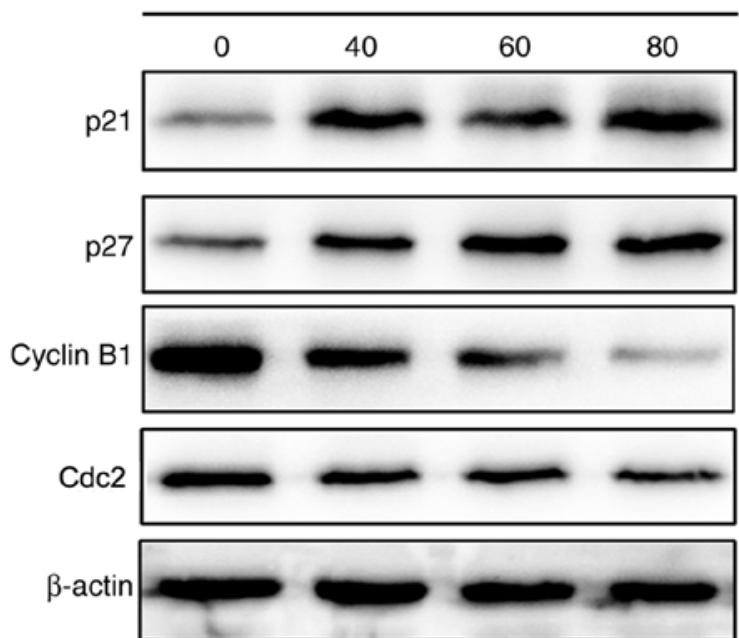

E

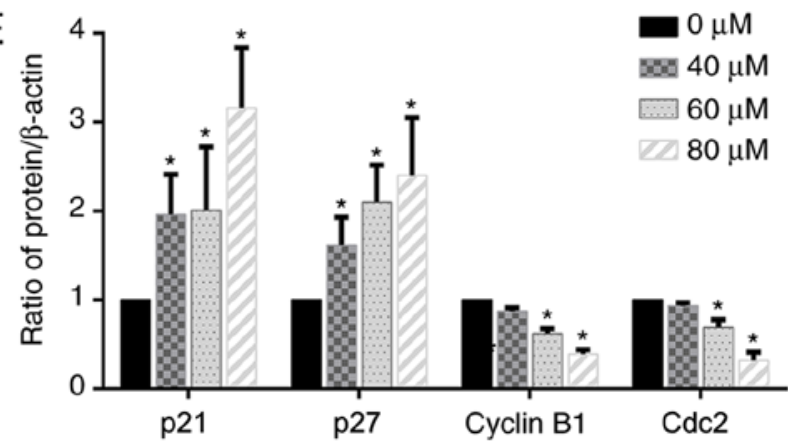

D
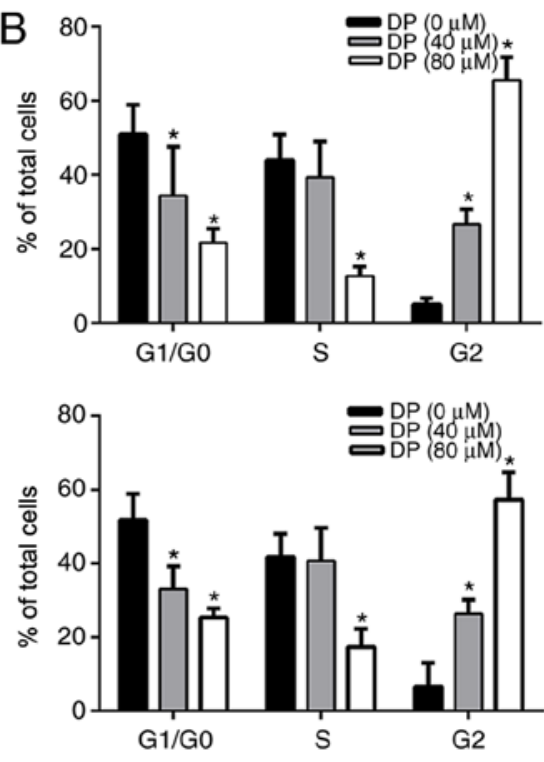

$\mathrm{DP}(80 \mu \mathrm{M})$

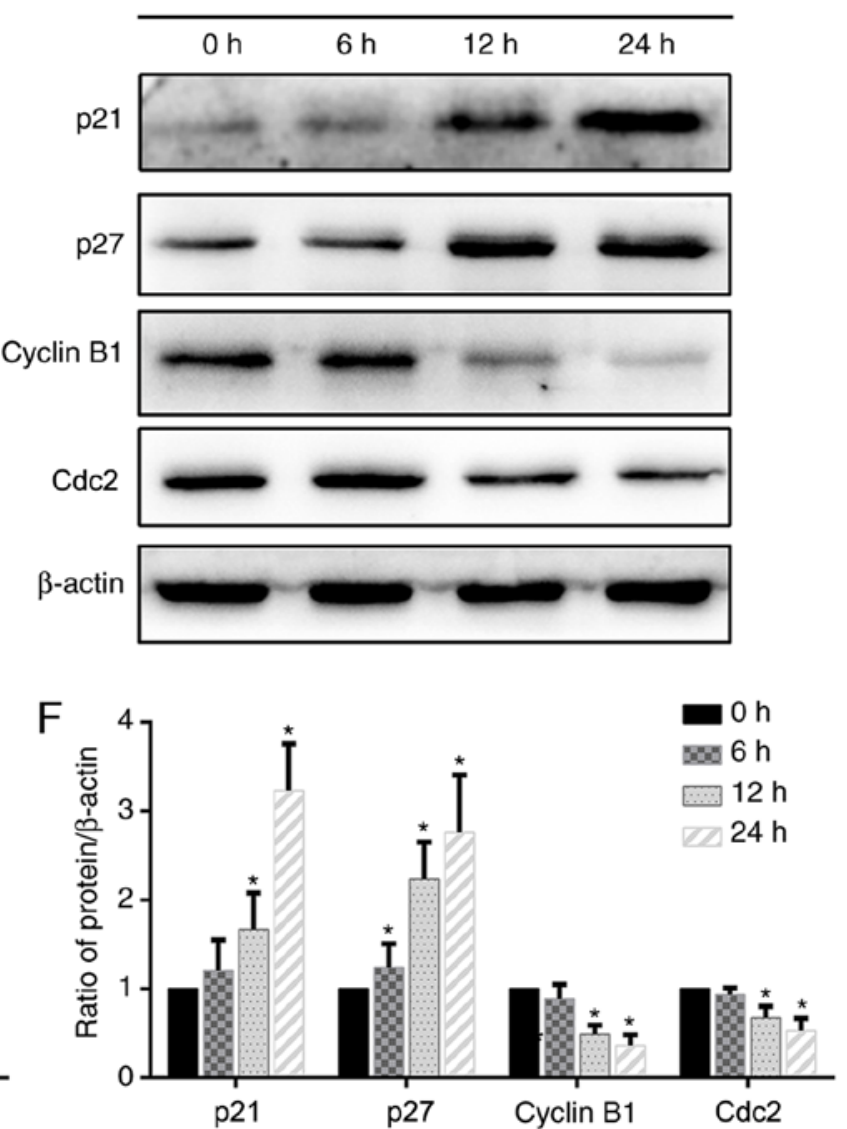

Figure 3. DP induces G2 phase cell cycle arrest in ESCC cells. (A and B) Flow cytometric analysis using PI staining showed that the cell cycle was blocked in the $\mathrm{G} 2 / \mathrm{M}$ phase after treatment with DP $(0,40$ and $80 \mu \mathrm{M})$ for $24 \mathrm{~h}$ in ECA109 and EC9706 cells. (C-F) A panel of G2/M phase-related protein was detected by western blot analysis. DP $(0,40,60$ and $80 \mu \mathrm{M})$ treatment for $24 \mathrm{~h}$ upregulated p21 and p27 expression and downregulated cyclin B1 and Cdc2 expression in a concentration- and time-dependent manner. The data are expressed as the mean \pm standard deviation ( $\mathrm{n}=3$ ). $\mathrm{P}<0.05$ compared with the control group. DP, dracorhodin perchlorate; ESCC, esophageal squamous cell carcinoma; PI, propidium iodide.

in ESCC cells, evidenced by the increased expression of DR4, DR5, cleaved caspase-3/-7/-9, and cleaved PARP, and decreased expression of total PARP, total caspase-3/7, Bcl-2 and caspase-9/-10. Bid is an important protein that transduces the apoptotic signal from the extrinsic to the intrinsic pathway by translocation of the truncated form (tBid) to mitochondria after cleavage by caspase- $8 /-10$, and it was demonstrated that Bid expression was reduced at the protein level after treatment with DP, indicating the presence of a crosstalk between extrinsic and intrinsic apoptosis (29). Furthermore, in the 
A
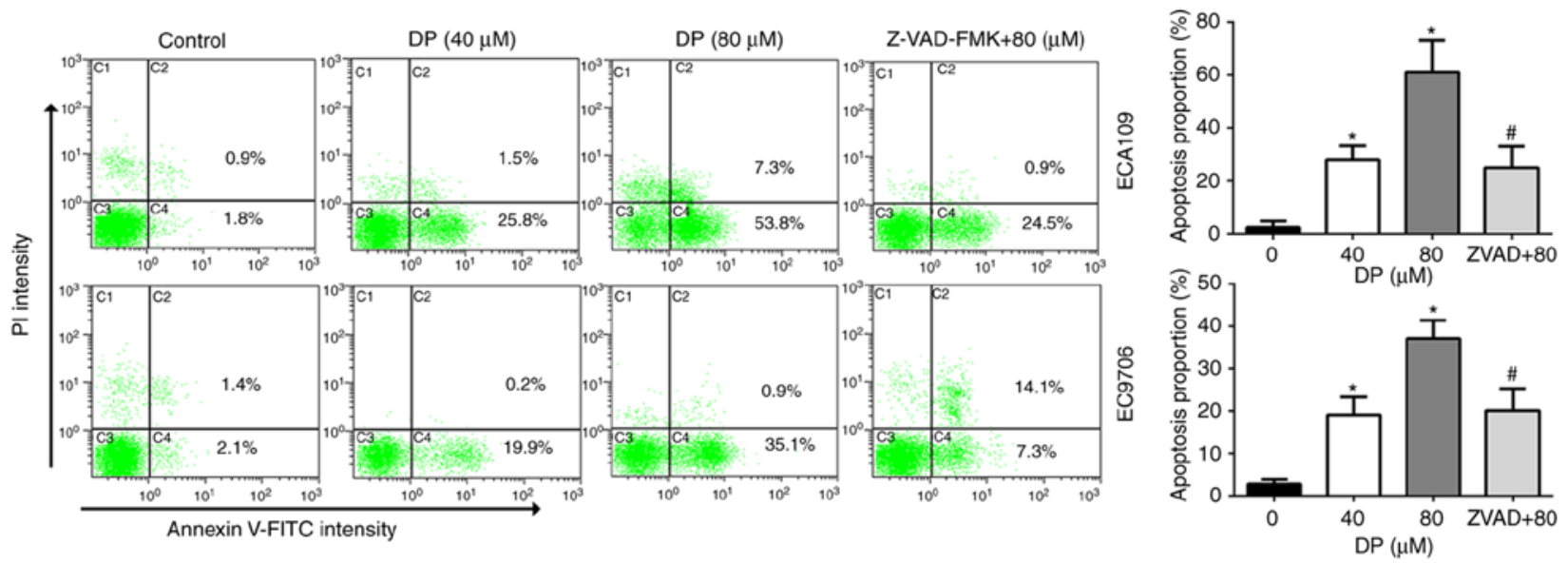

B
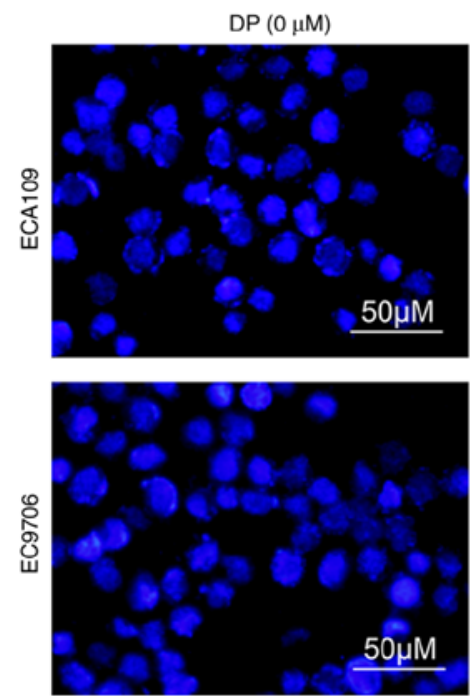
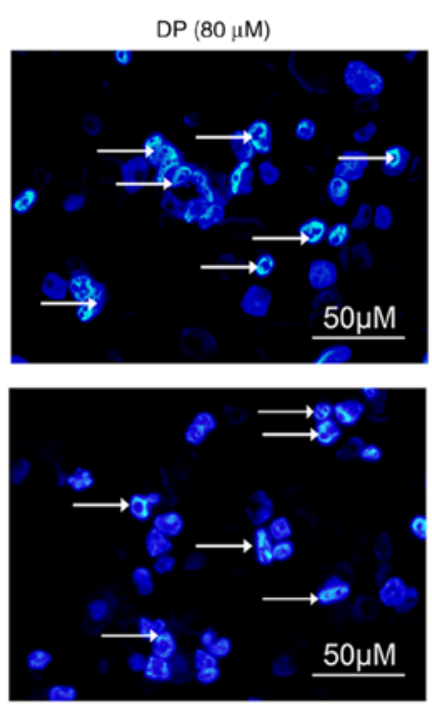

C

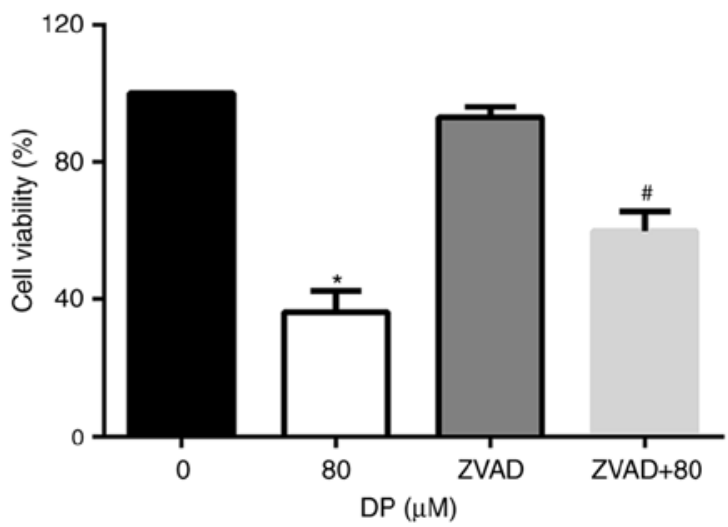

Figure 4. DP induces caspase-dependent apoptosis in ESCC cells. (A) Apoptosis was analyzed by flow cytometry using Annexin V-FITC/PI double staining assay. DP $(0,40$ and $80 \mu \mathrm{M})$ treatment for $24 \mathrm{~h}$ significantly increased the proportion of apoptotic cells that was reversed by pretreatment with Z-VAD-FMK for $1 \mathrm{~h}$ in ECA109 and EC9706 cells. (B) Morphological changes of apoptosis were observed under fluorescence microscope using Hoechst 33342 staining. After DP $(0$ and $80 \mu \mathrm{M})$ treatment for $24 \mathrm{~h}$, chromatin condensation and DNA fragmentation (as indicated by arrows), were observed in ECA109 and EC9706 cells. (C) After pretreatment with Z-VAD-FMK $(50 \mu \mathrm{M})$, reduction in cell viability mediated by DP treatment was partly reversed in ECA109 cells. The data are expressed as the mean \pm standard deviation $(n=3)$. ${ }^{*} \mathrm{P}<0.05$ vs. control; ${ }^{*} \mathrm{P}<0.05$ vs. DP treatment. DP, dracorhodin perchlorate; ESCC, esophageal squamous cell carcinoma. ZVAD+80, cells pretreated with Z-VAD-FMK and then treated with $80 \mu \mathrm{M}$ DP.

present study, DP-induced apoptosis of ESCC cells was found to occur in a caspase-dependent manner, as evidenced by the reversal of apoptosis mediated by Z-VAD-FMK, a caspase inhibitor. Our results are in accordance with previous studies reporting that DP induced apoptosis in multiple types of cancer cells $(15,17,18,30,31)$. However, which apoptotic pathway plays the most significant role in DP-induced apoptosis remains unknown and requires further investigation.

There is evidence that numerous signaling pathways are involved in the regulation of tumorigenesis, and the JAK2/STAT3 and AKT/FOXO3a signaling axes have been shown to play important roles in this process (32-34). The STAT3 transcription factor has been reported to be constitutively activated through phosphorylation by upstream JAK kinases in various cancer types, including lung cancer, melanoma, and esophageal cancer, in response to various stimuli such as cytokines and growth factors $(32,35)$. Activated STAT3 translocates to the nucleus where it promotes proliferation and cell cycle progression and inhibits apoptosis by activating the transcription of downstream oncogenes such as p21 and Bcl-2 (36,37). The AKT/FOXO3a signaling pathway is also involved in the regulation of multiple cellular functions. Once activated, AKT phosphorylates a variety of substrates, resulting in cell cycle progression and inhibition of apoptosis $(38,39)$; FOXO3a, meanwhile, is a transcription factor acting downstream of AKT, and its activity is inhibited by AKT-mediated phosphorylation, resulting in reduced transcription of key genes related to induction of apoptosis and cell cycle arrest $(40,41)$. Therefore, targeting these two signaling pathways has potential benefits for the development of new drugs.

In the present study, DP treatment was found to significantly inhibit the phosphorylation of JAK2, STAT3, AKT and FOXO3a. In addition, at the protein level, DP decreased JAK2 and STAT3 expression, whereas it had no obvious effect on AKT and FOXO3a expression. Treatment with DP also reduced Bcl-2 expression and increased p21 expression, both of which are regulated by AKT and STAT3. These results suggest that the JAK2/STAT3 and AKT/FOXO3a signaling pathways were involved, at least partly, in the regulation of apoptosis 
A

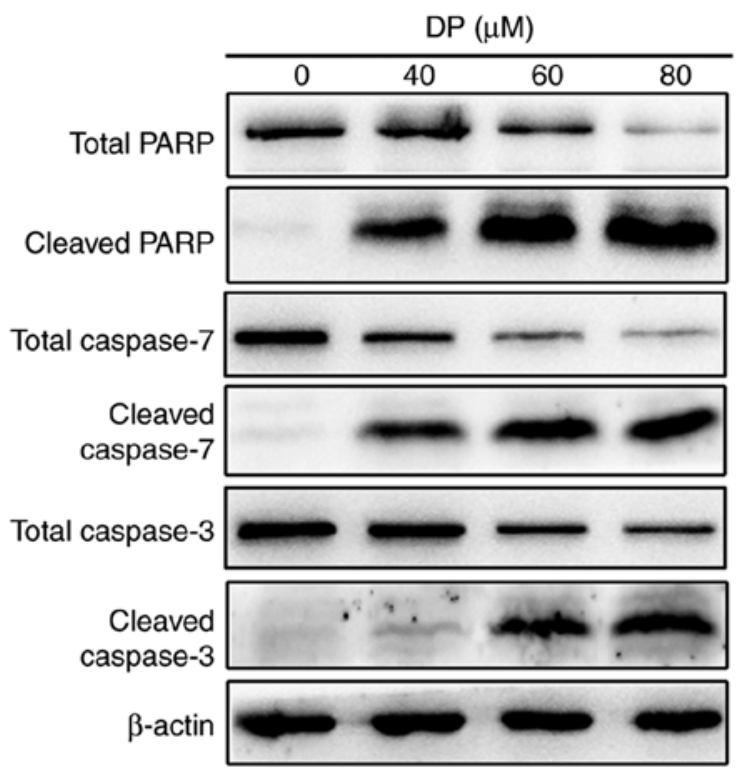

C

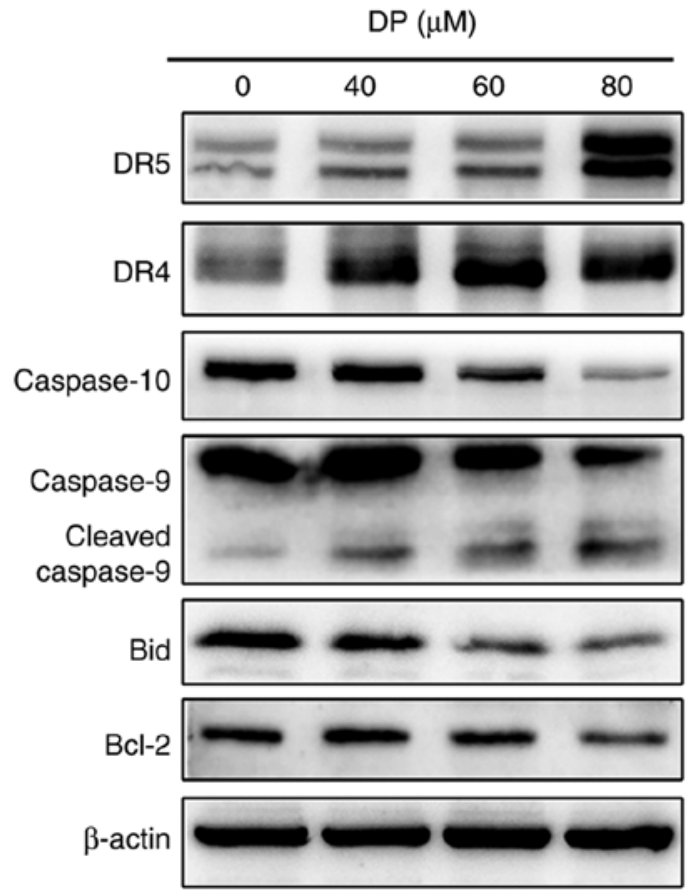

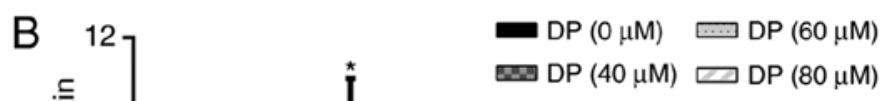

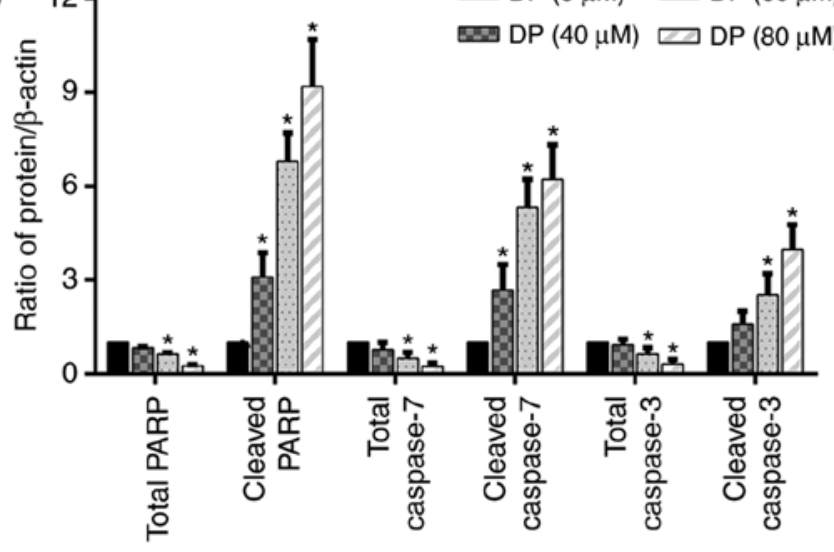

$\mathrm{D}$
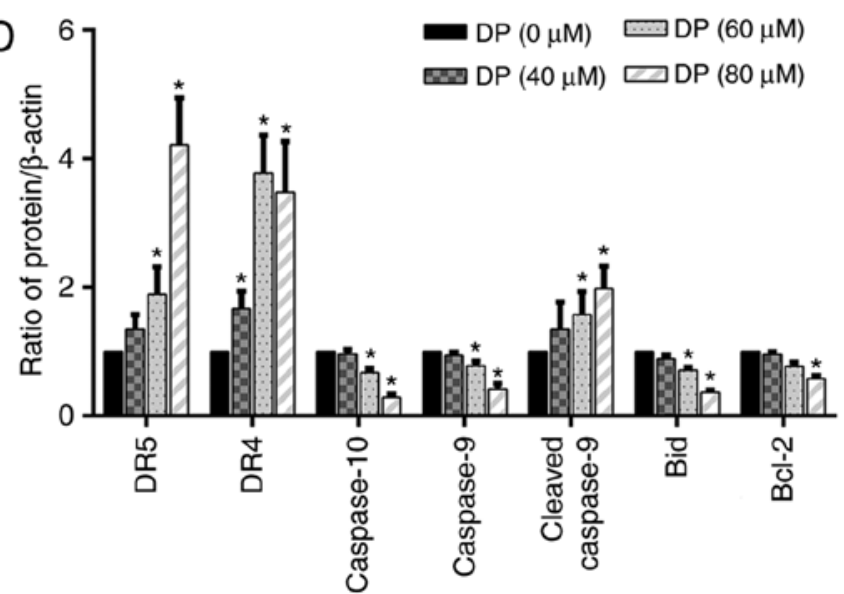

Figure 5. DP induces extrinsic and intrinsic apoptosis in ECA109 cells. ECA109 cells were treated DP $(0,40,60$ and $80 \mu \mathrm{M})$ for $24 \mathrm{~h}$. (A and B) The expression of PARP, caspase-3/7, cleaved PARP and cleaved-3/7 was detected by western blot analysis. (C and D) The expression of extrinsic apoptosis-related proteins DR5, DR4 and caspase-10, and intrinsic apoptosis-related proteins caspase-9, Bax and Bid were detected by western blot analysis. The data are expressed as the mean \pm standard deviation $(n=3)$. ${ }^{*} \mathrm{P}<0.05$ compared with the control group. DP, dracorhodin perchlorate; PARP, cleaved poly (ADP-ribose) polymerase; DR4, death receptor 4; DR5, death receptor 5 .

and cell cycle arrest induced by DP in ESCC cells. Our results are consistent with the findings of a previous study reporting that DP induced apoptosis in human gastric adenocarcinoma SGC-7901 cells via inhibition of AKT activity (15). Increasing evidence has shown that the STAT3 and AKT pathways exert their function interactively or independently in different cellular contexts $(42,43)$. Therefore, further experiments are needed to determine whether there is a crosstalk between the STAT3 and AKT pathways in DP-treated ESCC cells.

The ideal drug for the treatment of cancer should efficiently inhibit cancer cell proliferation but have little cytotoxicity on normal cells. In the present study, DP showed a more potent cytotoxic effect on ESCC cells compared with human normal liver cell, yet one limitation of our study was that the cytotoxicity of DP on esophageal epithelial cells was not confirmed.

In conclusion, in the present study, DP was found to reduce the viability and inhibit the proliferation of ESCC cells. In addition, DP treatment induced extrinsic and intrinsic apoptosis, and resulted in cell cycle arrest at the G2/M phase. Moreover, the JAK2/STAT3 and AKT/FOXO3a signaling pathways were inhibited by DP treatment. Together, our results indicate that DP is a promising agent for use in the development of new drugs to treat ESCC. 
A

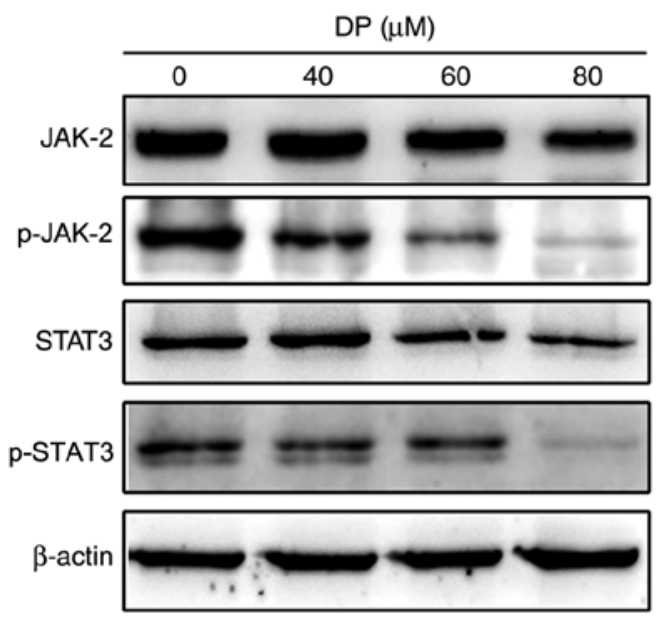

B

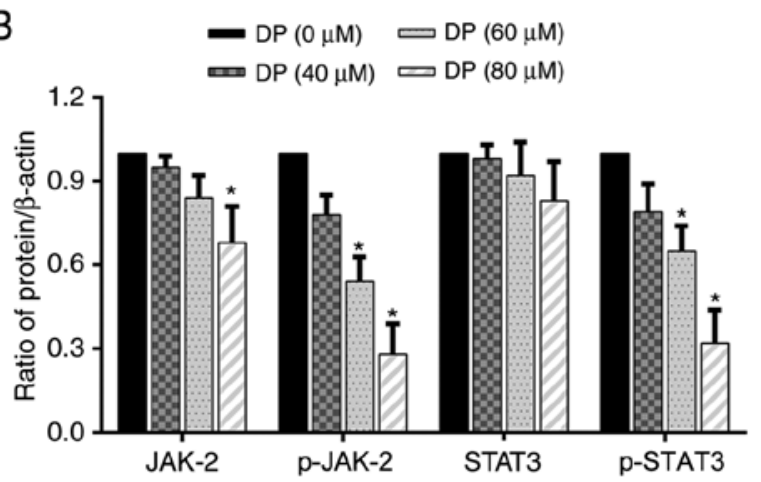

C

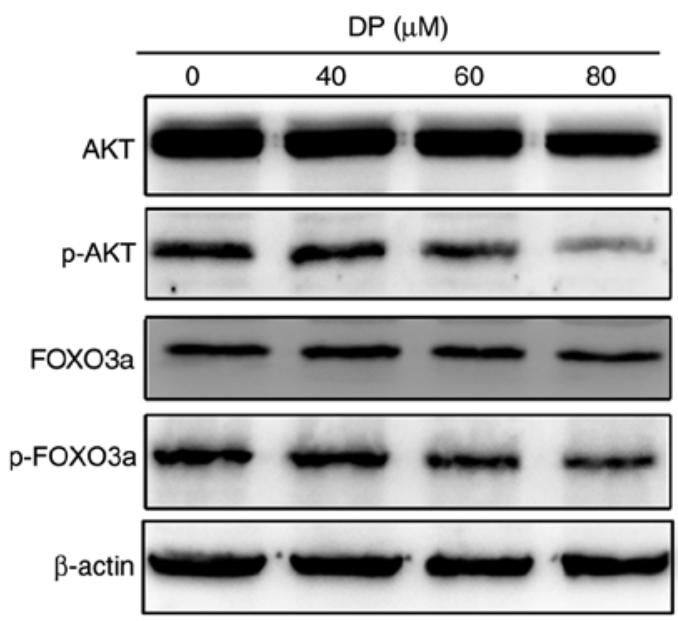

D

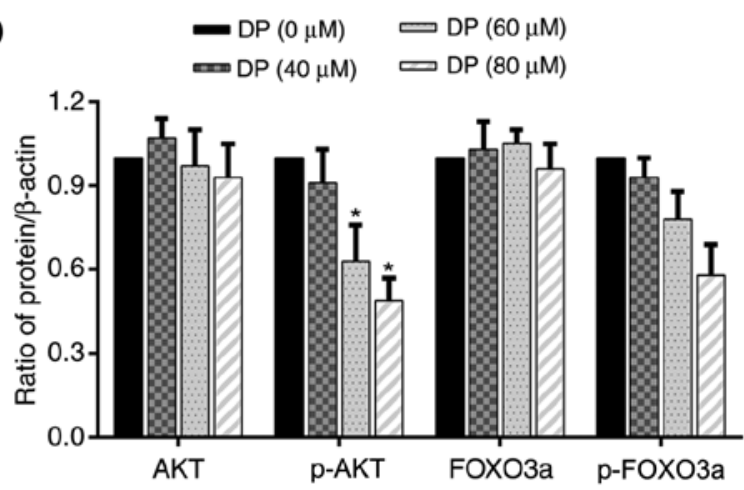

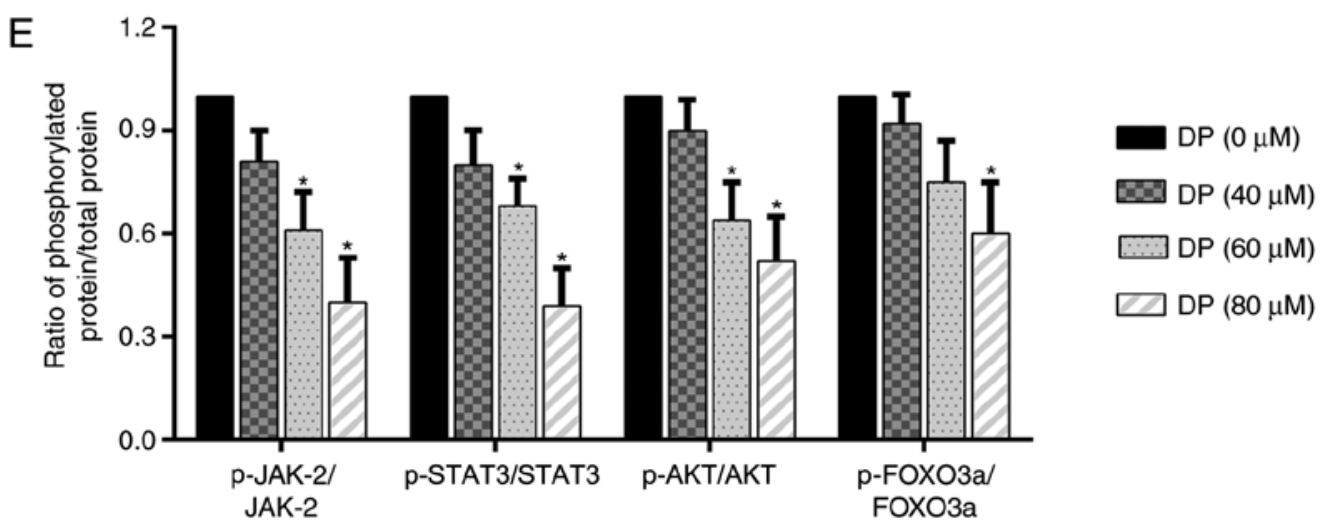

Figure 6. DP inhibits the JAK2/STAT3 and AKT/FOXO3a signaling pathways in ECA109 cells. ECA109 cells were treated DP $(0,40,60$ and $80 \mu \mathrm{M})$ for $24 \mathrm{~h}$. (A and B) Phosphorylation and expression of JAK2 and STAT3 were determined using western blot analysis. (C and D) Phosphorylation and expression of AKT and FOXO3a were determined using western blot analysis. (E) The ratio of phosphorylated protein/total protein (p-JAK2/JAK2, p-STAT3/STAT3, p-AKT/AKT, p-FOXO3a/FOXO3a). The data are expressed as the mean \pm standard deviation $(n=3)$. " $\mathrm{P}<0.05$ compared with the control group. DP, dracorhodin perchlorate; JAK2, Janus kinase 2; STAT3, signal transducer and activator of transcription 3; FOXO3a, forkhead box O3a.

\section{Acknowledgements}

Not applicable.

\section{Funding}

The present study was supported by a grant from the National Natural Science Foundation of China (no. 81702975).

\section{Availability of data and materials}

All data generated or analyzed during this study are included in this published article.

\section{Authors' contributions}

ZL wrote the paper. ZL, CLi, CLu and YJ performed the experiments. ZL, YL and CLu analyzed the data. GZ designed the experiments and improved the manuscript. All authors read and approved the manuscript and agree to be accountable for all aspects of the research in ensuring that the accuracy or integrity of any part of the work are appropriately investigated and resolved.

\section{Ethics approval and consent to participate}

Not applicable. 


\section{Patient consent for publication}

Not applicable.

\section{Competing interests}

The authors declare that they have no competing interests.

\section{References}

1. Torre LA, Bray F, Siegel RL, Ferlay J, Lortet-Tieulent J and Jemal A: Global cancer statistics, 2012. CA Cancer J Clin 65: 87-108, 2015.

2. Chen W, Zheng R, Baade PD, Zhang S, Zeng H, Bray F, Jemal A, Yu XQ and He J: Cancer statistics in China, 2015. CA Cancer J Clin 66: 115-132, 2016.

3. Ohashi S, Miyamoto S, Kikuchi O, Goto T, Amanuma Y and Muto M: Recent advances from basic and clinical studies of esophageal squamous cell carcinoma. Gastroenterology 149: 1700-1715, 2015.

4. Pennathur A, Gibson MK, Jobe BA and Luketich JD: Oesophageal carcinoma. Lancet 381: 400-412, 2013.

5. Chang H, Shin SK, Cho BC, Lee CG, Kim CB, Kim DJ, Lee JG, Hur J, Lee CY, Bae MK, et al: A prospective phase II trial of S-1 and cisplatin-based chemoradiotherapy for locoregionally advanced esophageal cancer. Cancer Chemother Pharmacol 73: 665-671, 2014

6. Zhu X, Li Z, Li T, Long F, Lv Y, Liu L, Liu X and Zhan Q: Osthole inhibits the PI3K/AKT signaling pathway via activation of PTEN and induces cell cycle arrest and apoptosis in esophageal squamous cell carcinoma. Biomed Pharmacother 102: 502-509, 2018

7. Lin S, Lv J, Peng P, Cai C, Deng J, Deng H, Li X and Tang X: Bufadienolides induce p53-mediated apoptosis in esophageal squamous cell carcinoma cells in vitro and in vivo. Oncol Lett 15: 1566-1572, 2018.

8. Jiang JH, Pi J, Jin H, Yang F and Cai JY: Chinese herb medicine matrine induce apoptosis in human esophageal squamous cancer KYSE-150 cells through increasing reactive oxygen species and inhibiting mitochondrial function. Pathol Res Pract 214: 691-699, 2018.

9. Siyo V, Schäfer G, Hunter R, Grafov A, Grafova I, Nieger M, Katz AA, Parker MI and Kaschula CH: The cytotoxicity of the ajoene analogue BisPMB in WHCO1 oesophageal cancer cells is mediated by CHOP/GADD153. Molecules 22: E892, 2017.

10. Brockmann H and Junge H: Die konstitution des dracorhodins, eines neuen farbstoffes aus dem 'Drachenblut'. Berl Dtsch Chem Ges 76: 751-846, 1943.

11. Rao GS, Gerhart MA, Lee RT III, Mitscher LA and Drake S: Antimicrobial agents from higher plants. Dragon's blood resin. J Nat Prod 45: 646-648, 1982.

12. Li F, Jiang T, Liu W, Hu Q and Yin H: The angiogenic effect of dracorhodin perchlorate on human umbilical vein endothelial cells and its potential mechanism of action. Mol Med Rep 14: $1667-1672,2016$

13. Jiang XW, Qiao L, Liu L, Zhang BQ, Wang XW, Han YW and $\mathrm{Yu}$ WH: Dracorhodin perchlorate accelerates cutaneous wound healing in wistar rats. Evid Based Complement Alternat Med 2017: 8950516, 2017.

14. Yang LF, Liu X, Lv LL, Ma ZM, Feng XC and Ma TH: Dracorhodin perchlorate inhibits biofilm formation and virulence factors of Candida albicans. J Mycol Med 28: 36-44, 2018.

15. Rasul A, Ding C, Li X, Khan M, Yi F, Ali M and Ma T: Dracorhodin perchlorate inhibits PI3K/Akt and NF- $\kappa$ B activation, up-regulates the expression of p53, and enhances apoptosis. Apoptosis 17: 1104-1119, 2012.

16. Xia M, Wang M, Tashiro S, Onodera S, Minami M and Ikejima T: Dracorhodin perchlorate induces A375-S2 cell apoptosis via accumulation of p53 and activation of caspases. Biol Pharm Bull 28: 226-232, 2005.

17. Chen X, Luo J, Meng L, Pan T, Zhao B, Tang ZG and Dai Y: Dracorhodin perchlorate induces the apoptosis of glioma cells. Oncol Rep 35: 2364-2372, 2016.

18. Zhang G, Sun M, Zhang Y, Hua P, Li X, Cui R and Zhang X: Dracorhodin perchlorate induces G1/G0 phase arrest and mitochondria-mediated apoptosis in SK-MES-1 human lung squamous carcinoma cells. Oncol Lett 10: 240-246, 2015.

19. Yu JH, Zheng GB, Liu CY, Zhang LY, Gao HM, Zhang YH, Dai CY, Huang L, Meng XY, Zhang WY and Yu XF: Dracorhodin perchlorate induced human breast cancer MCF-7 apoptosis through mitochondrial pathways. Int J Med Sci 10: 1149-1156, 2013.
20. Molinari M: Cell cycle checkpoints and their inactivation in human cancer. Cell Prolif 33: 261-274, 2000.

21. Kastan MB and Bartek J: Cell-cycle checkpoints and cancer. Nature 432: 316-323, 2004.

22. Diaz-Moralli S, Tarrado-Castellarnau M, Miranda A and Cascante M: Targeting cell cycle regulation in cancer therapy. Pharmacol Ther 138: 255-271, 2013.

23. Shaltiel IA, Krenning L, Bruinsma W and Medema RH: The same, only different-DNA damage checkpoints and their reversal throughout the cell cycle. J Cell Sci 128: 607-620, 2015.

24. Hochegger H, Takeda S and Hunt T: Cyclin-dependent kinases and cell-cycle transitions: Does one fit all? Nat Rev Mol Cell Biol 9: 910-916, 2008.

25. Wood SJ, Goldufsky JW, Bello D, Masood S and Shafikhani SH: Pseudomonas aeruginosa ExoT induces mitochondrial apoptosis in target host cells in a manner that depends on its GTPase-activating protein (GAP) domain activity. J Biol Chem 290: 29063-29073, 2015.

26. Nguyen JT and Wells JA: Direct activation of the apoptosis machinery as a mechanism to target cancer cells. Proc Natl Acad Sci USA 100: 7533-7538, 2003.

27. Wong RS: Apoptosis in cancer: From pathogenesis to treatment. J Exp Clin Cancer Res 30: 87, 2011.

28. Ola MS, Nawaz M and Ahsan H: Role of Bcl-2 family proteins and caspases in the regulation of apoptosis. Mol Cell Biochem 351: 41-58, 2011.

29. Lemke J, von Karstedt S, Zinngrebe $J$ and Walczak H: Getting TRAIL back on track for cancer therapy. Cell Death Differ 21: 1350-1364, 2014

30. Xia MY, Wang MW, Cui Z, Tashiro SI, Onodera S, Minami M and Ikejima T: Dracorhodin perchlorate induces apoptosis in HL-60 cells. J Asian Nat Prod Res 8: 335-343, 2006.

31. He Y, Ju W, Hao H, Liu Q, Lv L and Zeng F: Dracorhodin perchlorate suppresses proliferation and induces apoptosis in human prostate cancer cell line PC-3. J Huazhong Univ Sci Technolog Med Sci 31: 215, 2011.

32. Huynh J, Etemadi N, Hollande F, Ernst M and Buchert M: The JAK/STAT3 axis: A comprehensive drug target for solid malignancies. Semin Cancer Biol 45: 13-22, 2017.

33. Johnson DE, O'Keefe RA and Grandis JR: Targeting the IL-6/JAK/STAT3 signalling axis in cancer. Nat Rev Clin Oncol 15: 234-248, 2018.

34. Prabhu VV,AllenJE,DickerDT andEl-Deiry WS: Small-molecule ONC201/TIC10 targets chemotherapy-resistant colorectal cancer stem-like cells in an Akt/Foxo3a/TR AIL-dependent manner. Cancer Res 75: 1423-1432, 2015.

35. Siveen KS, Sikka S, Surana R, Dai X, Zhang J, Kumar AP, Tan BK, Sethi G and Bishayee A: Targeting the STAT3 signaling pathway in cancer: Role of synthetic and natural inhibitors. Biochim Biophys Acta 1845: 136-154, 2014.

36. Wei Z, Jiang X, Qiao H, Zhai B, Zhang L, Zhang Q, Wu Y, Jiang $\mathrm{H}$ and Sun X: STAT3 interacts with Skp2/p27/p21 pathway to regulate the motility and invasion of gastric cancer cells. Cell Signal 25: 931-938, 2013.

37. Ma J, Song X, Xu X and Mou Y: Cancer-associated-fibroblasts promote the chemo-resistance in gastric cancer through secreting IL-11 targeting JAK/STAT3/Bcl2 pathway. Cancer Res Treat 51: 194-210, 2019.

38. Steelman LS, Pohnert SC, Shelton JG, Franklin RA, Bertrand FE and McCubrey JA: JAK/STAT, Raf/MEK/ERK, PI3K/Akt and BCR-ABL in cell cycle progression and leukemogenesis. Leukemia 18: 189-218, 2004.

39. New DC, Wu K, Kwok AW and Wong YH: G protein-coupled receptor-induced Akt activity in cellular proliferation and apoptosis. FEBS J 274: 6025-6036, 2007.

40. Rathbone CR, Booth FW and Lees SJ: FoxO3a preferentially induces $\mathrm{p} 27 \mathrm{Kip} 1$ expression while impairing muscle precursor cell-cycle progression. Muscle Nerve 37: 84-89, 2008.

41. Zhang X, Tang N, Hadden TJ and Rishi AK: Akt, FoxO and regulation of apoptosis. Biochim Biophys Acta 1813: 1978-1986, 2011.

42. Li Y, Cui N, Zheng PS and Yang WT: BMX/Etk promotes cell proliferation and tumorigenicity of cervical cancer cells through PI3K/AKT/mTOR and STAT3 pathways. Oncotarget 8: 49238-49252, 2017.

43. Steelman LS, Abrams SL, Whelan J, Bertrand FE, Ludwig DE, Bäsecke J, Libra M, Stivala F, Milella M, Tafuri A, et al: Contributions of the Raf/MEK/ERK, PI3K/PTEN/Akt/mTOR and Jak/STAT pathways to leukemia. Leukemia 22: 686-707, 2008.

This work is licensed under a Creative Commons Attribution-NonCommercial-NoDerivatives 4.0 International (CC BY-NC-ND 4.0) License. 